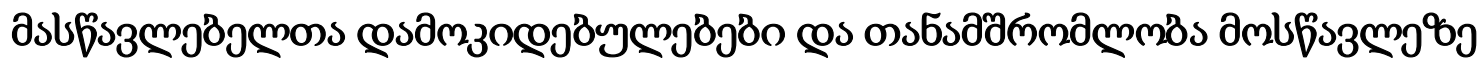 мஙু
}

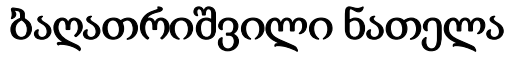

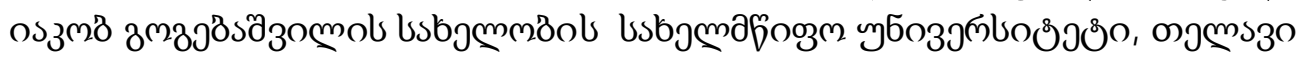

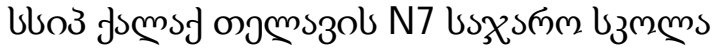

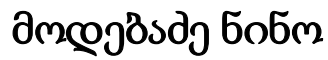

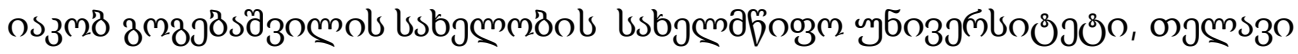

https://doi.org/10.52340/idw .2021.534

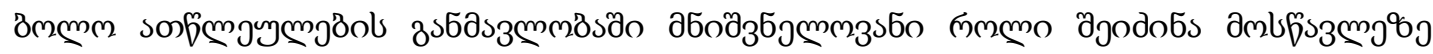

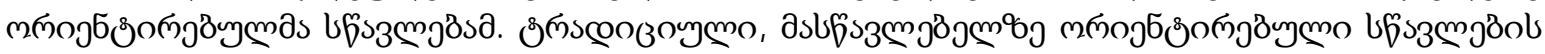

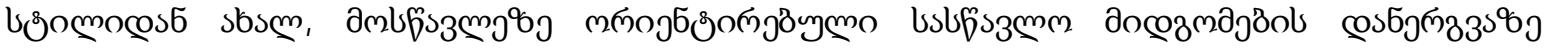

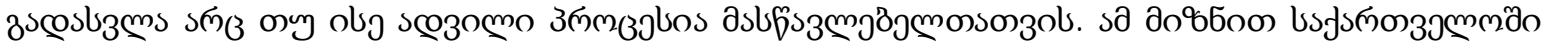

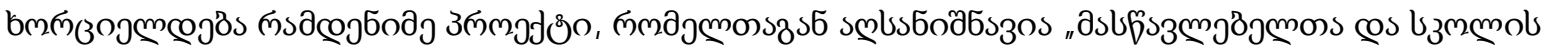

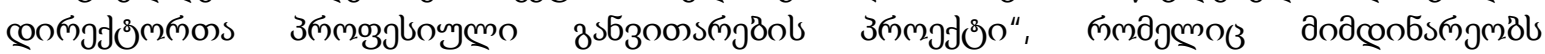

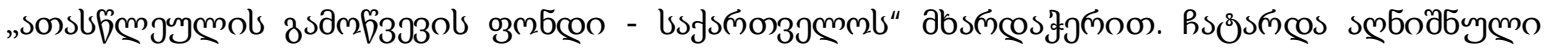

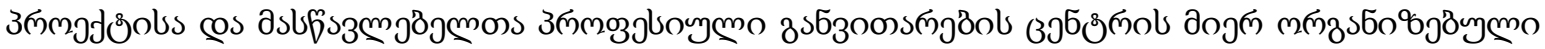

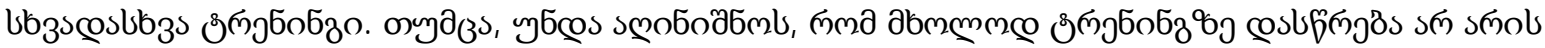

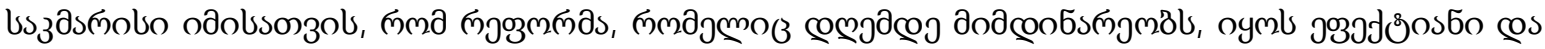

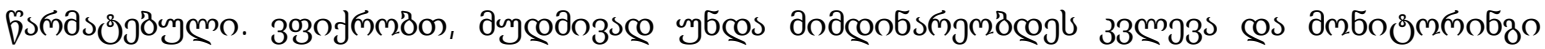

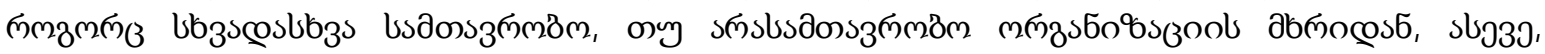

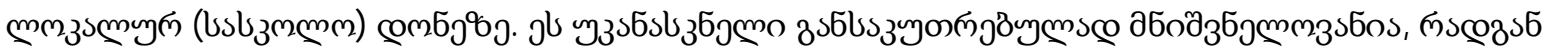

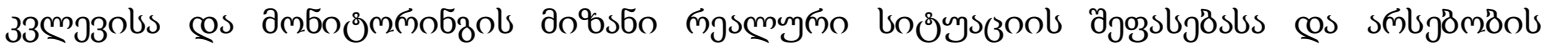

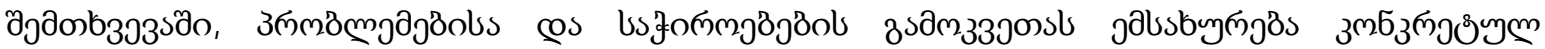

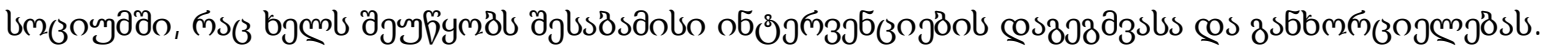

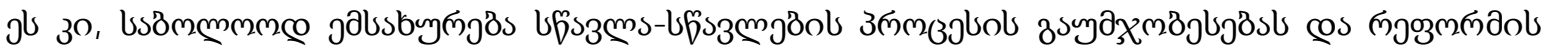

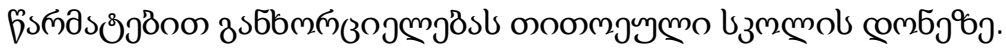

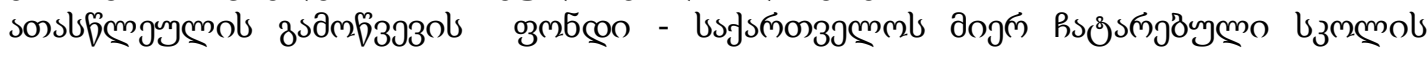

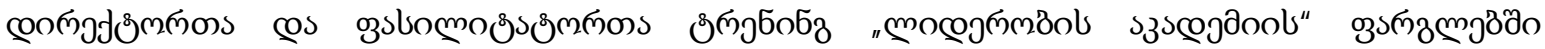

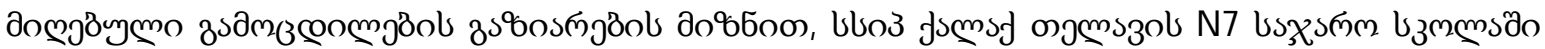

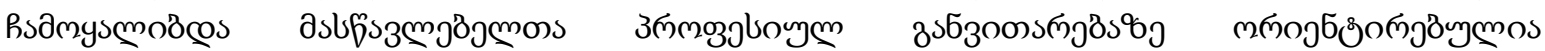

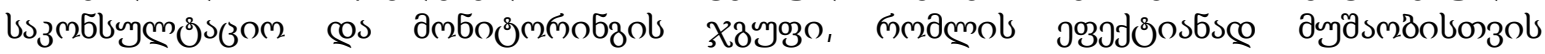

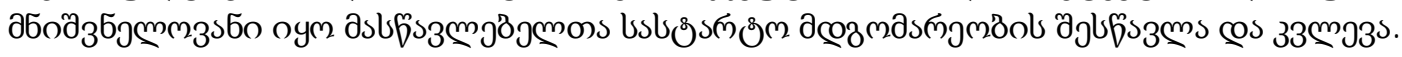

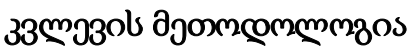

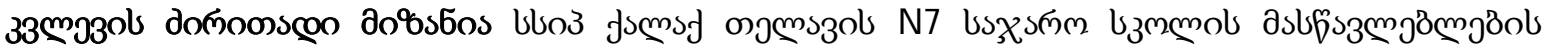

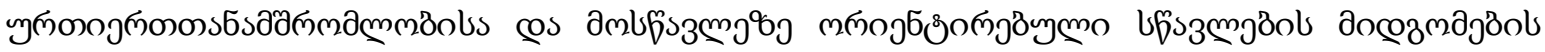

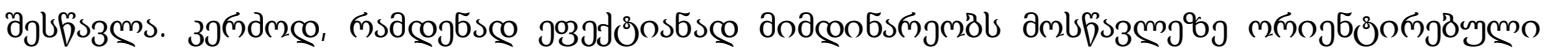

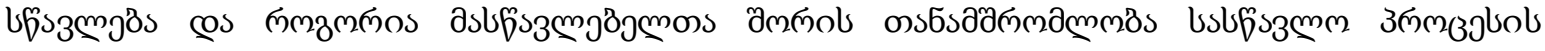

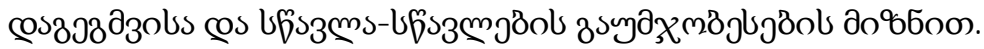

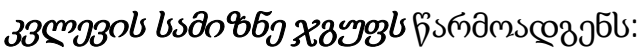

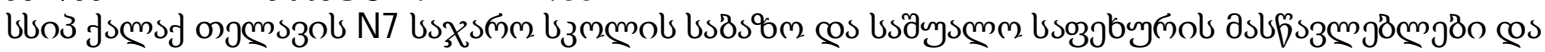

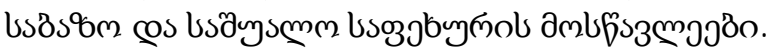




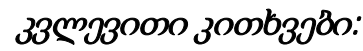

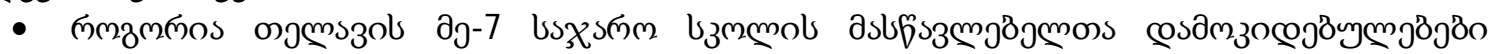

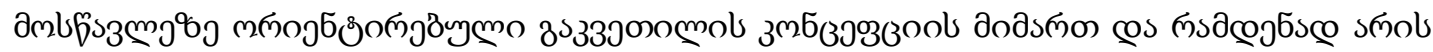

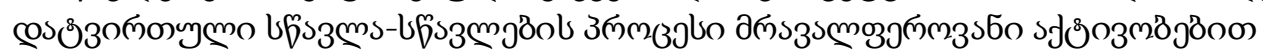

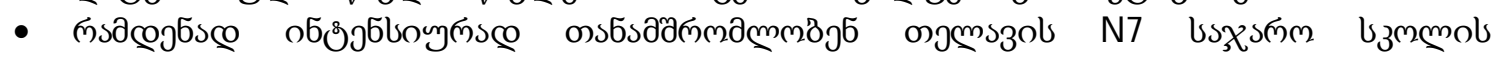

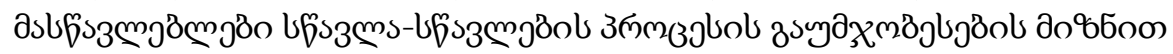

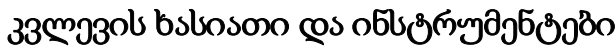

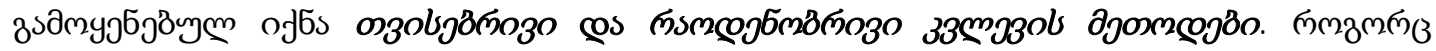

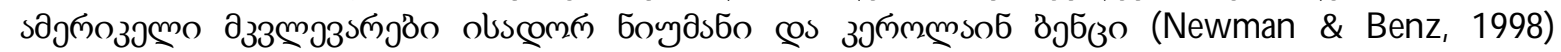

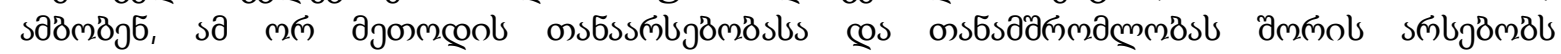

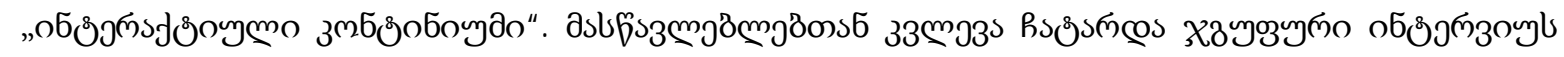

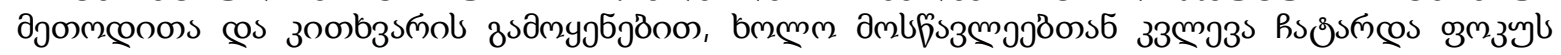

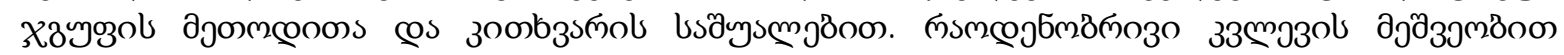

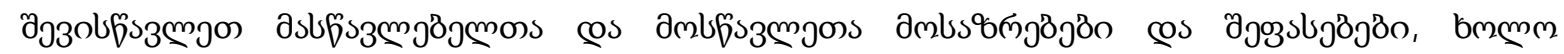

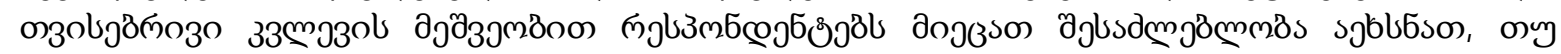

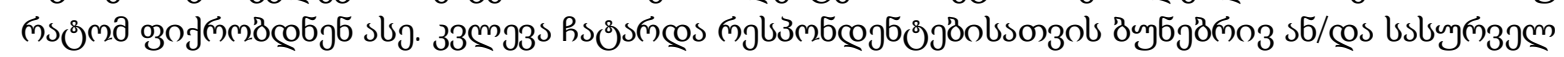

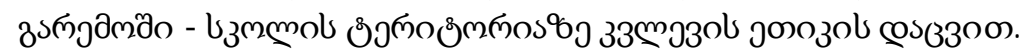

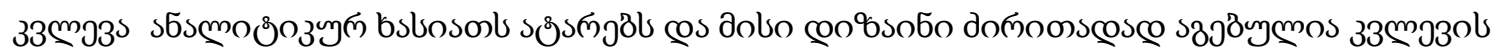

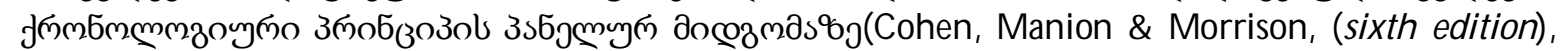

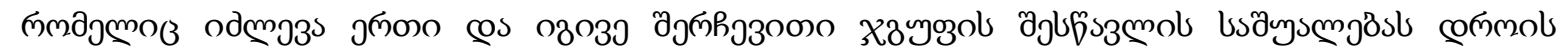

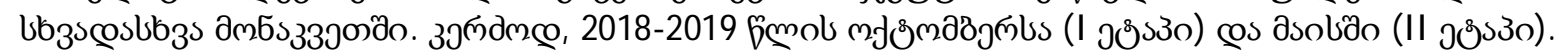

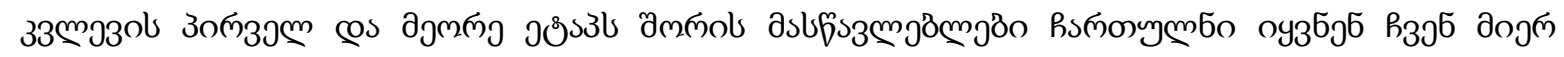

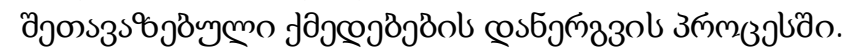

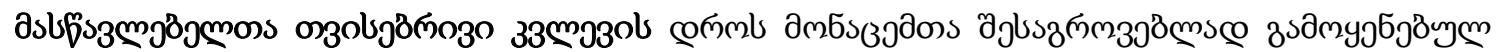

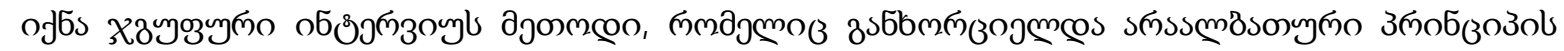

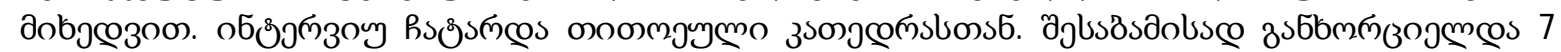

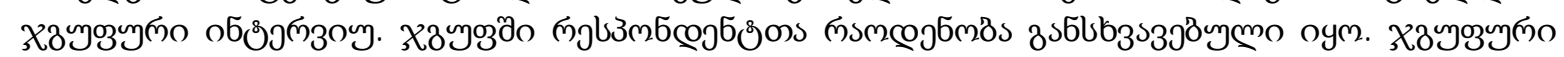
oб

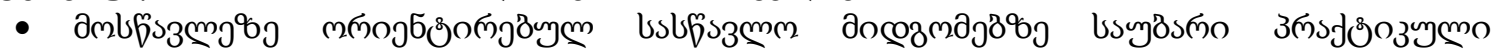

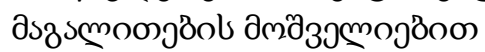

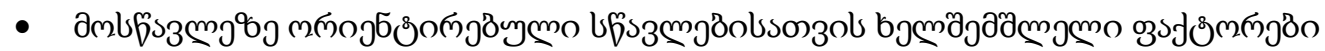

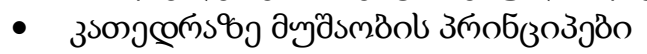

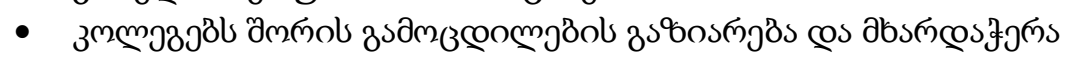

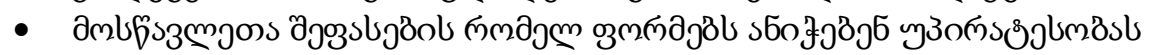

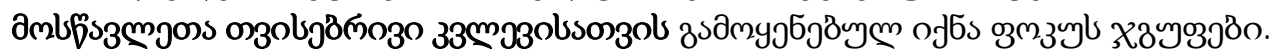

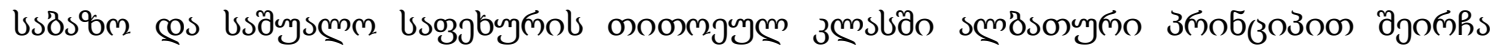

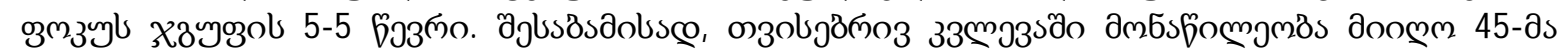

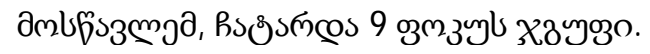

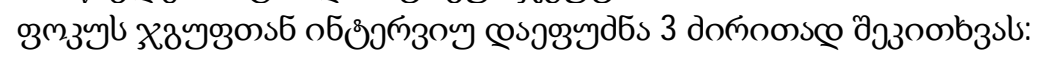

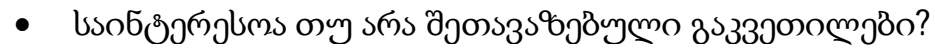

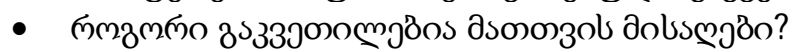

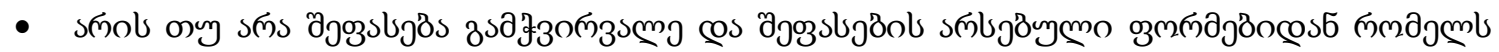
sБо

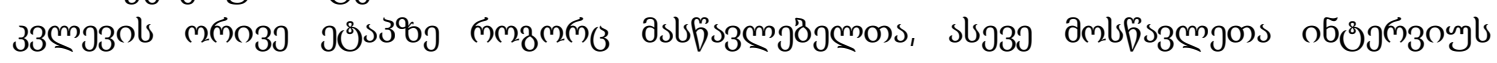

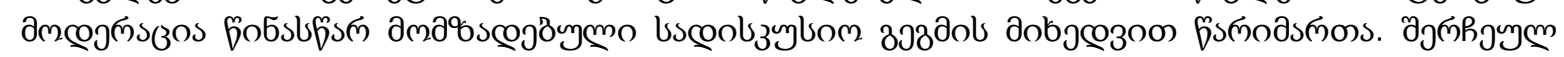

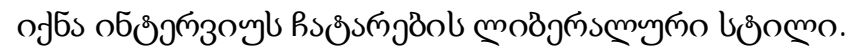

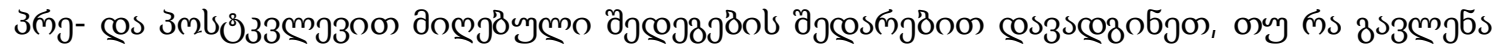

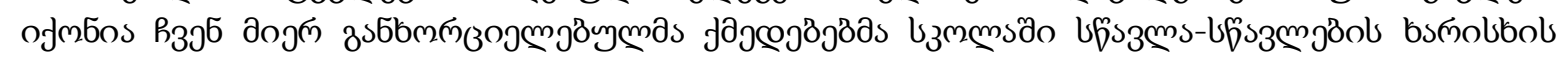

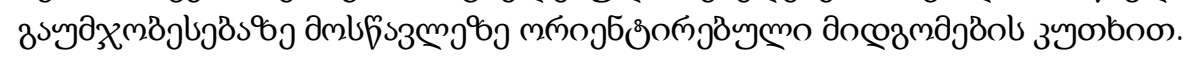




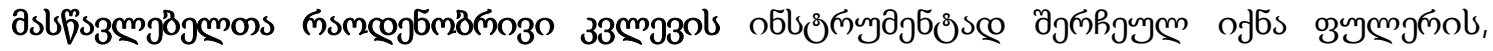

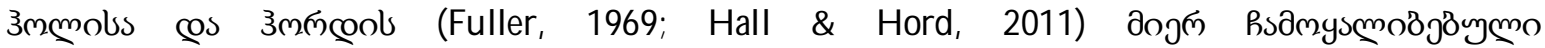

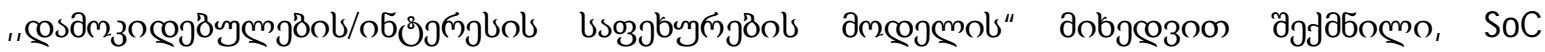

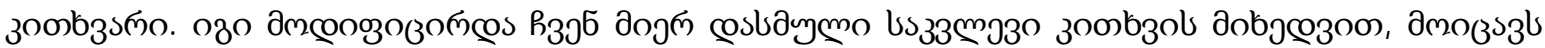

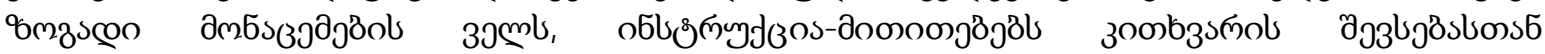

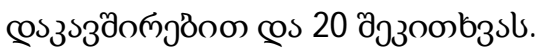

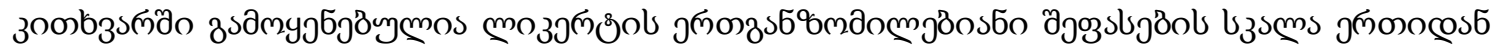

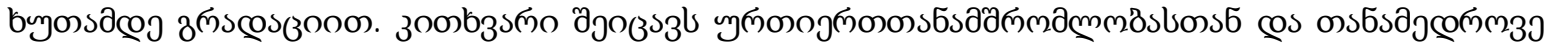

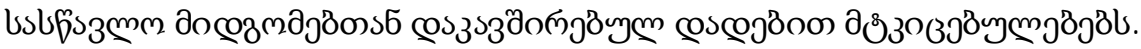

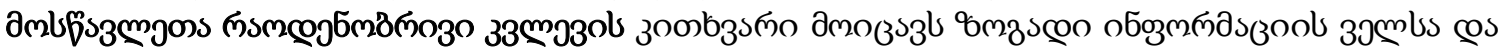

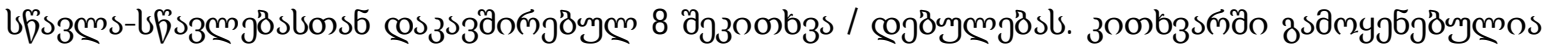

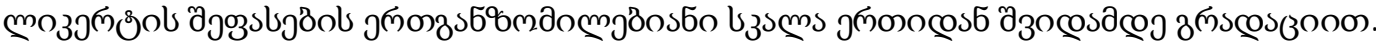

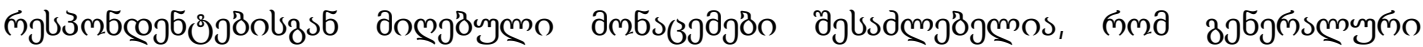

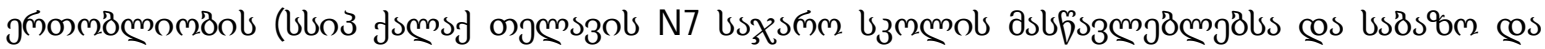

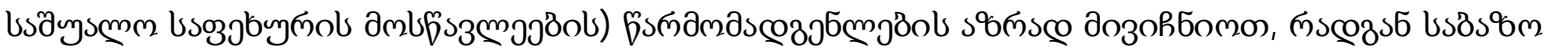

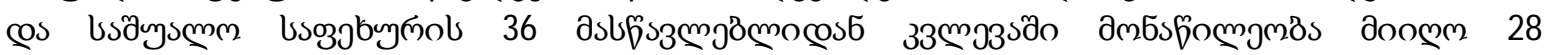

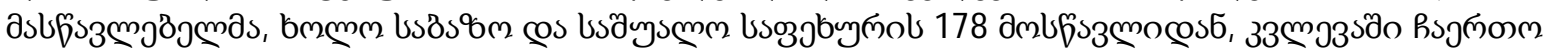
119 ambfosmon.

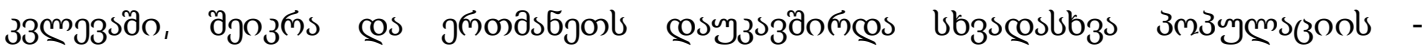

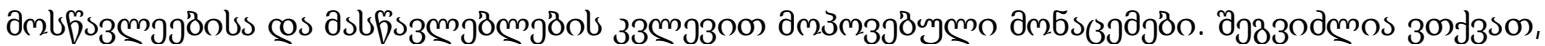

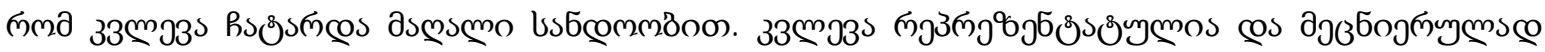

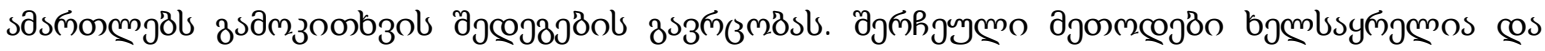

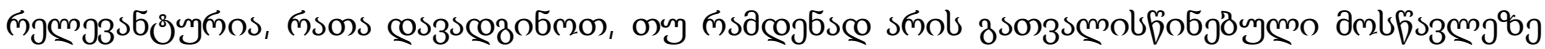

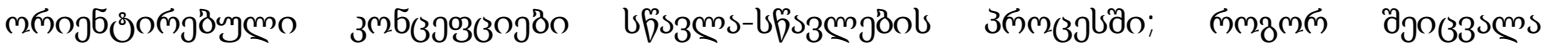

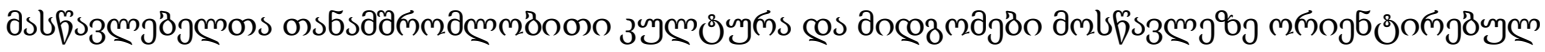

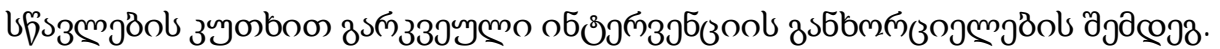

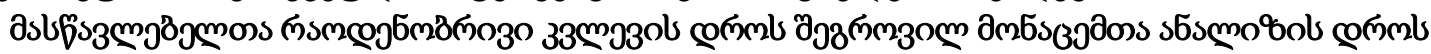

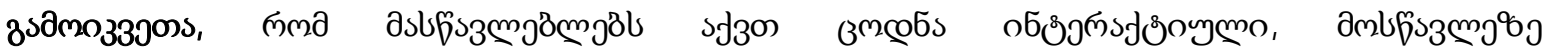

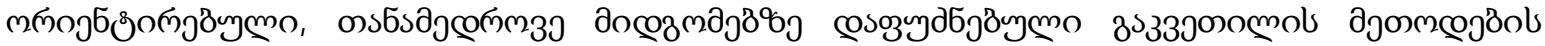

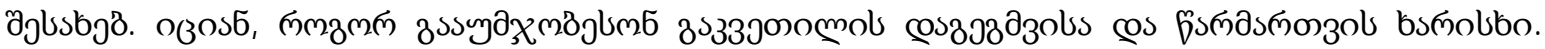

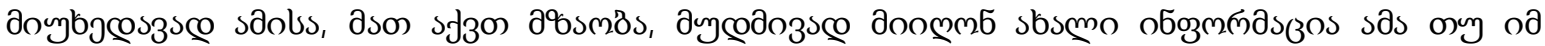

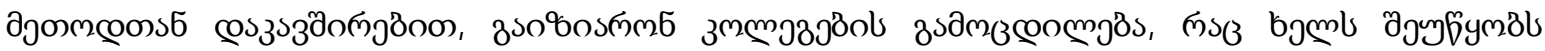

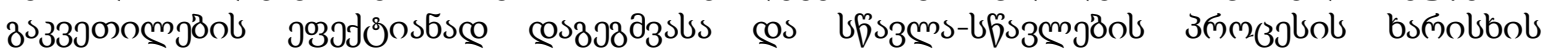

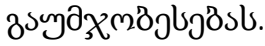

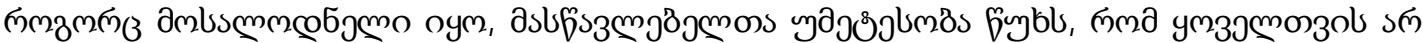

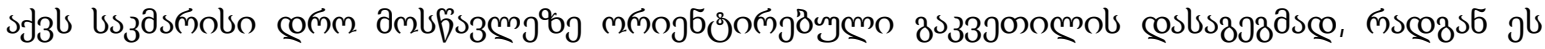

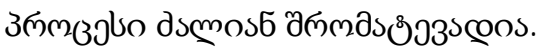

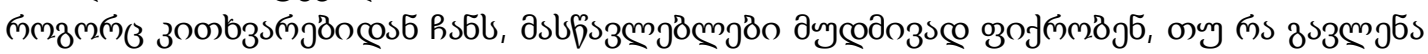

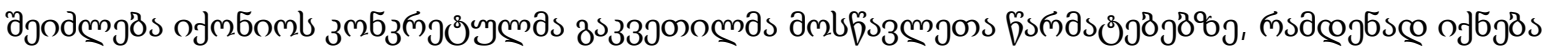

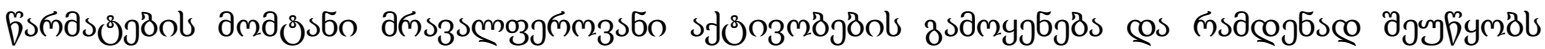

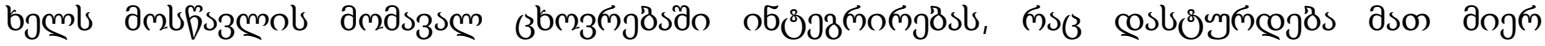

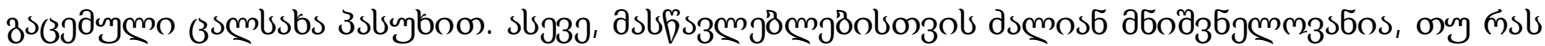

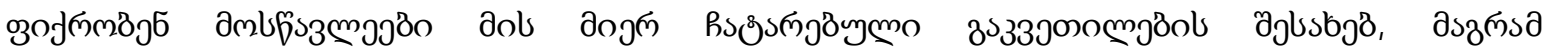

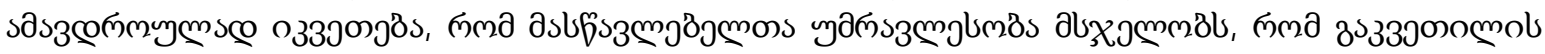

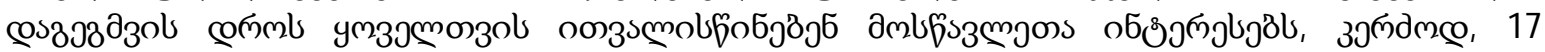

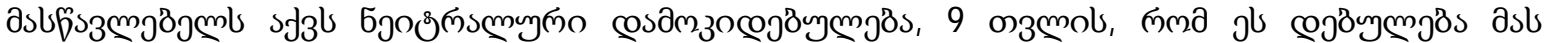

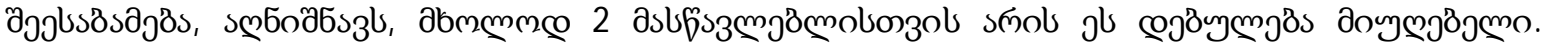

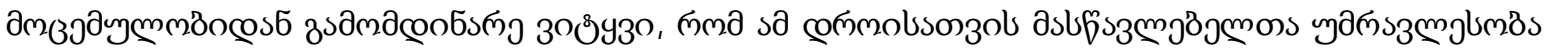

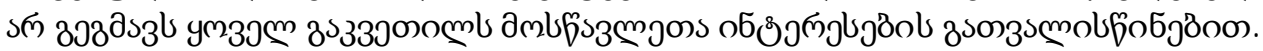




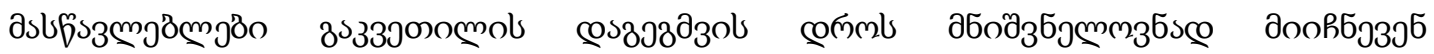

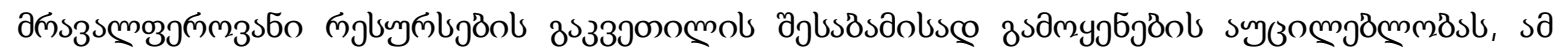

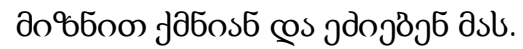

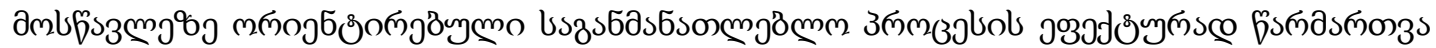

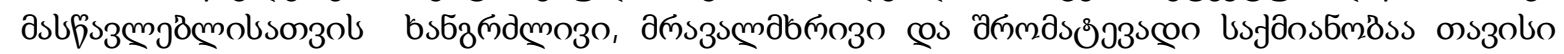

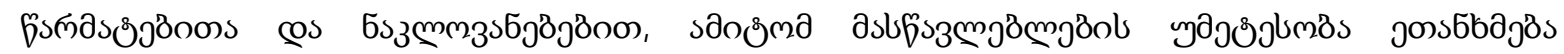

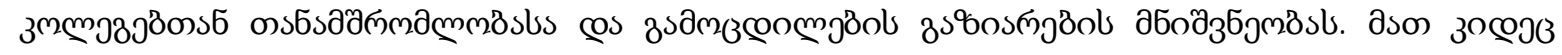

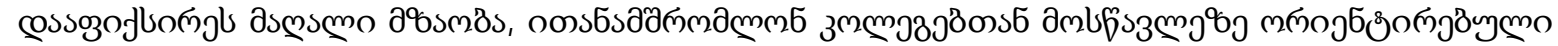

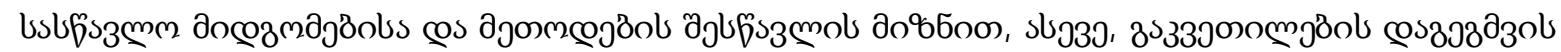

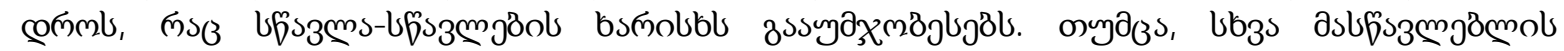

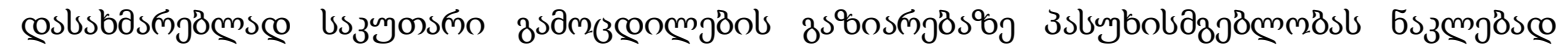

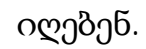

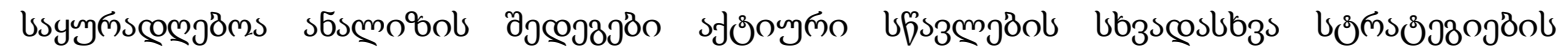

17. ?? ? ??? ????

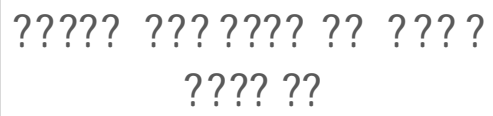

???? ??

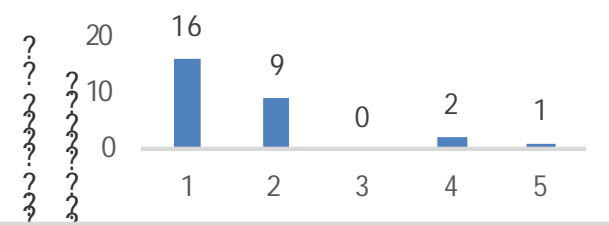

19. ??? ???? ?

? ?? ????? ? ?

????? ??????? ...

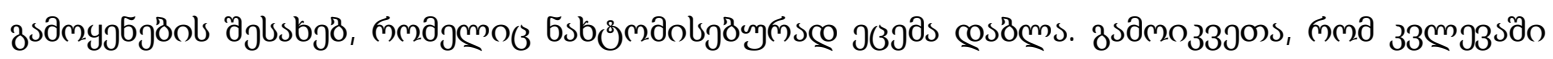

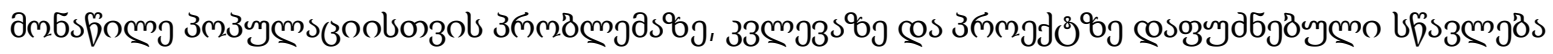

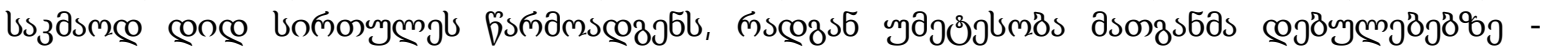
з3мэз

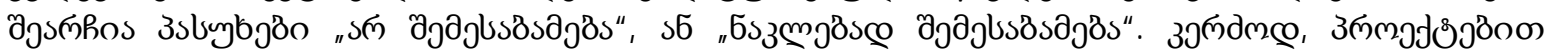

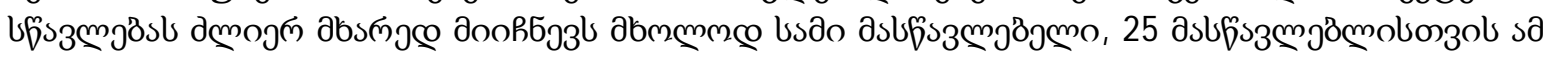

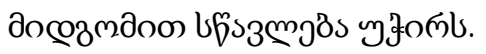

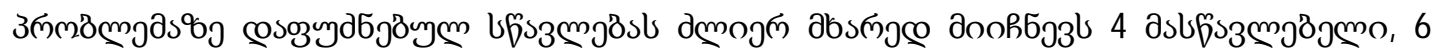

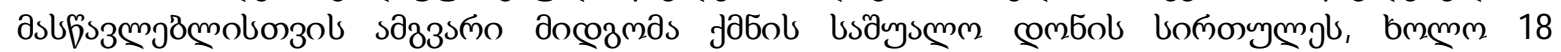

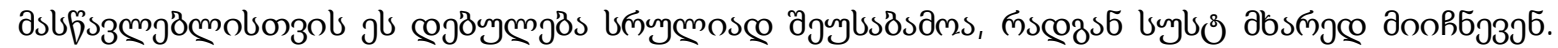

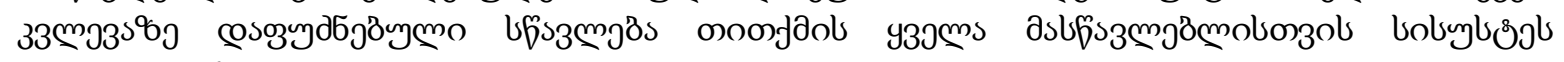

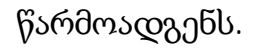

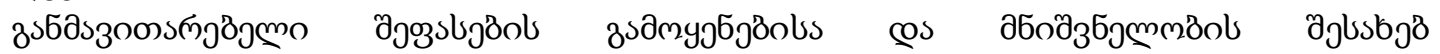

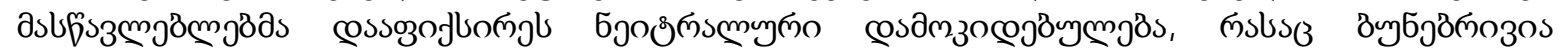

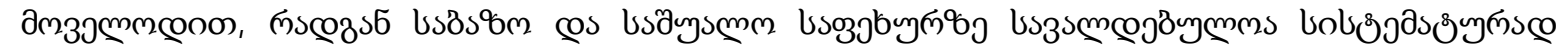

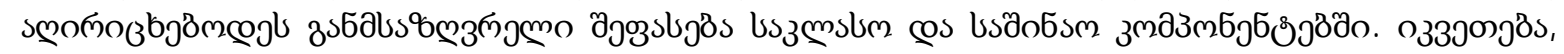

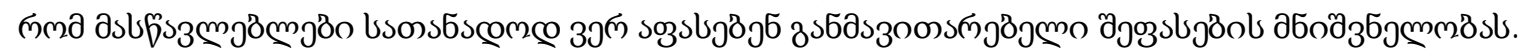

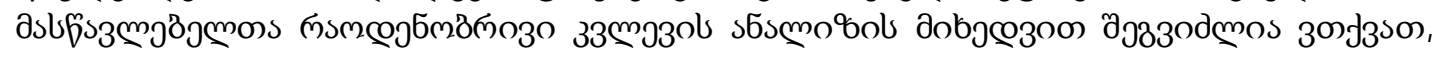

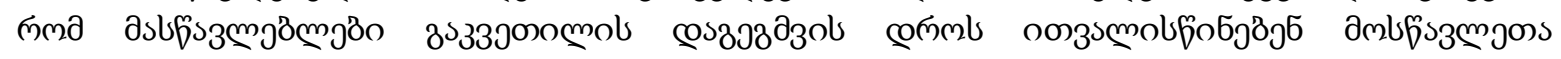

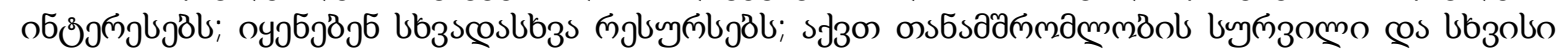

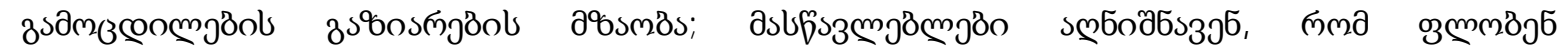

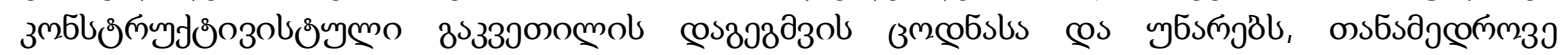

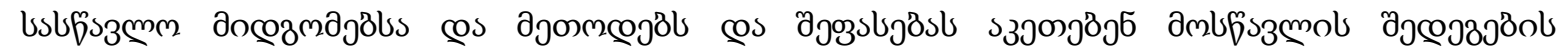

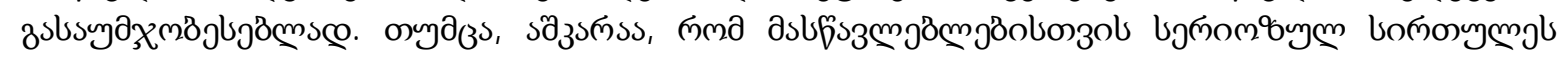

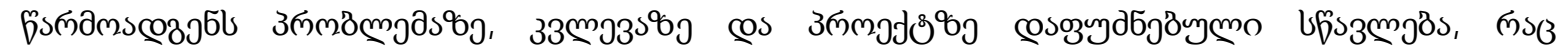

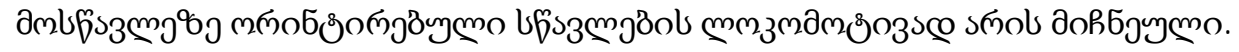




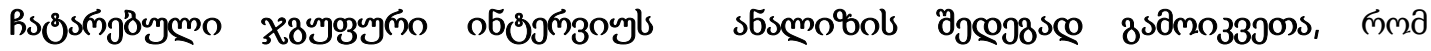

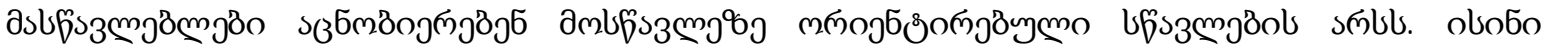

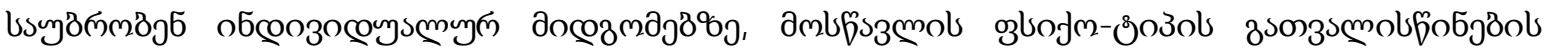

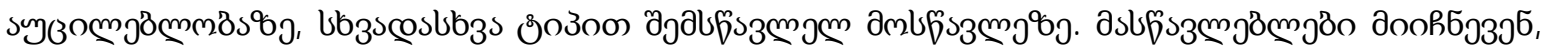

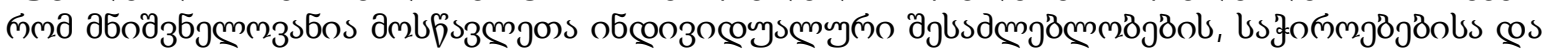

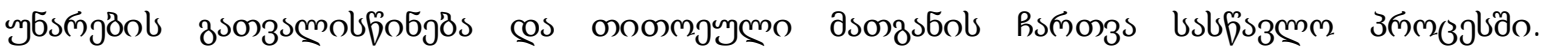

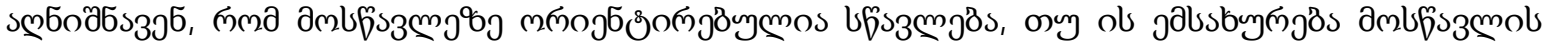

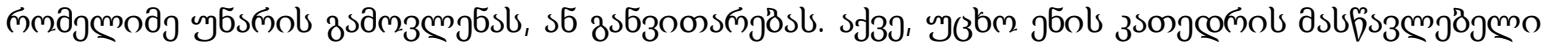

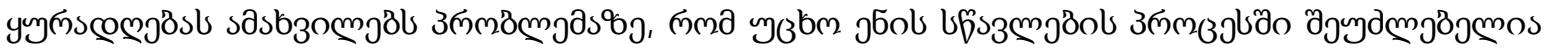

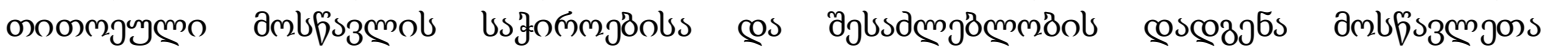

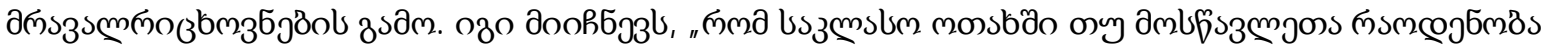

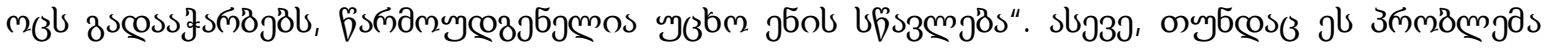

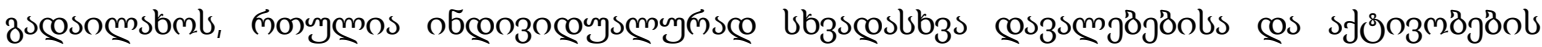

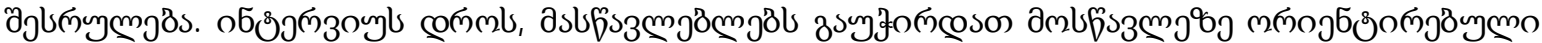

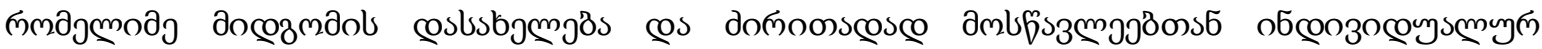

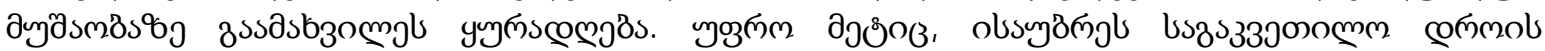

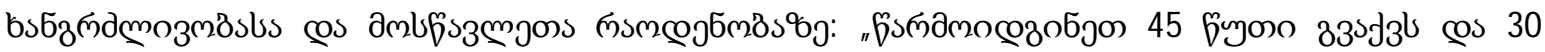

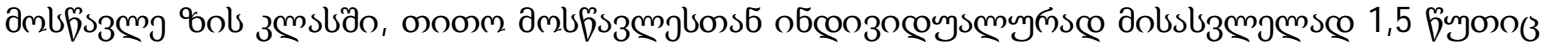

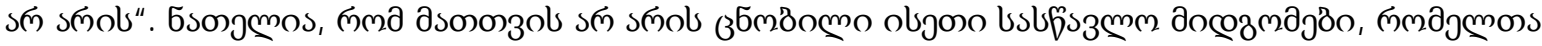

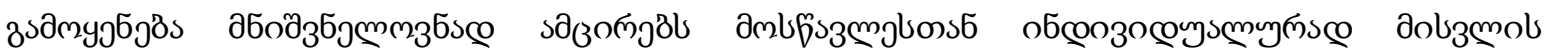

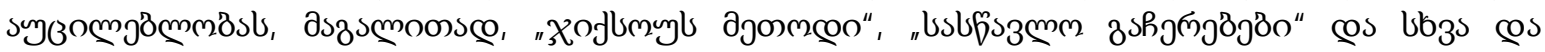

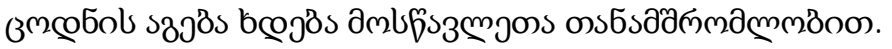

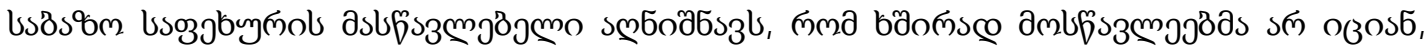

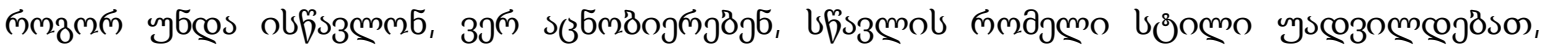

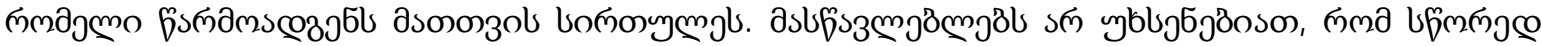

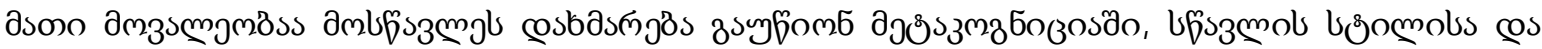

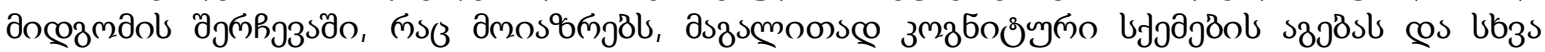

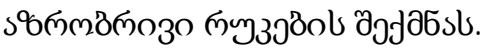

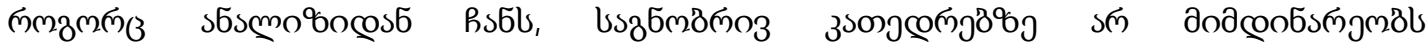

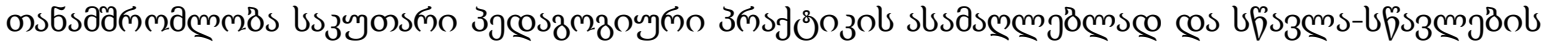

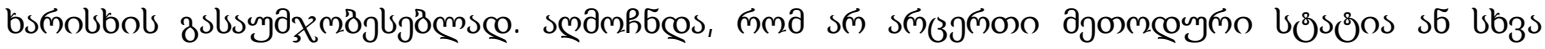

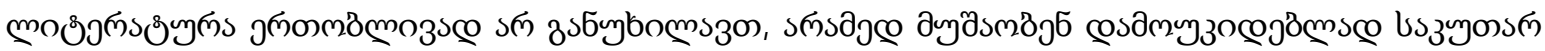
os 3 \%े.

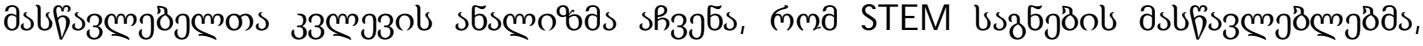

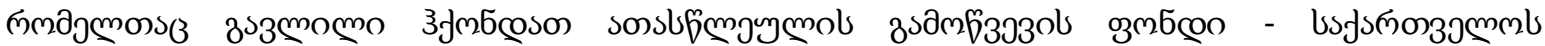

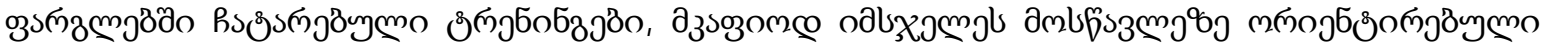

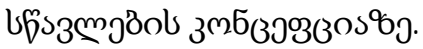

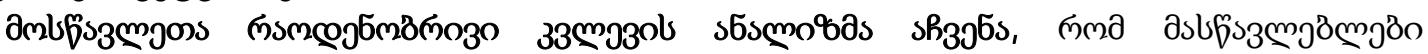

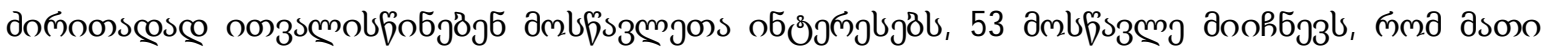

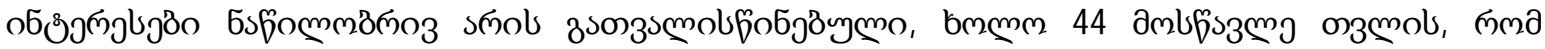

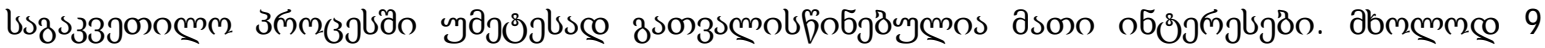

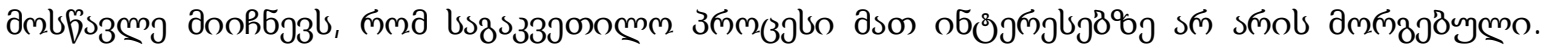

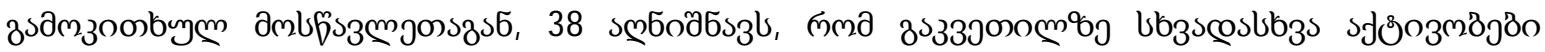

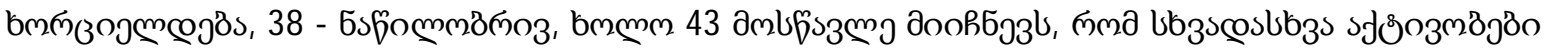

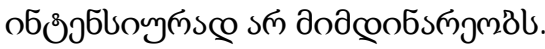

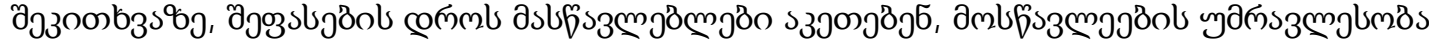

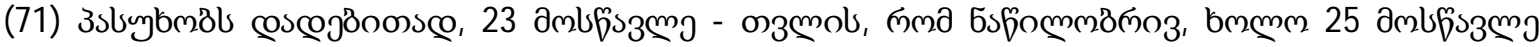

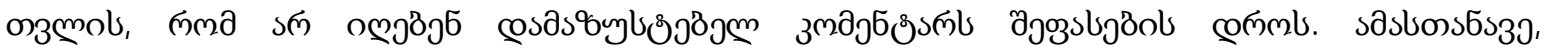

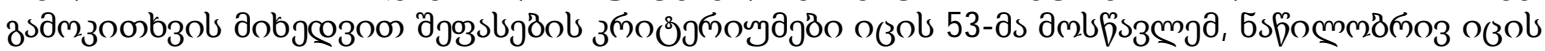

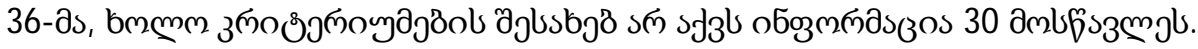




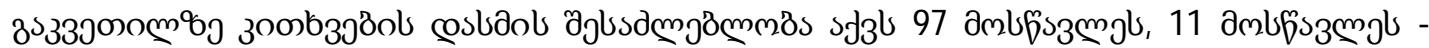

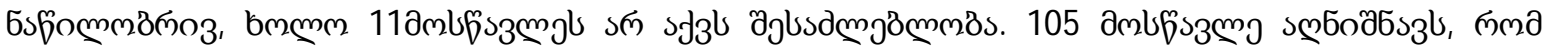

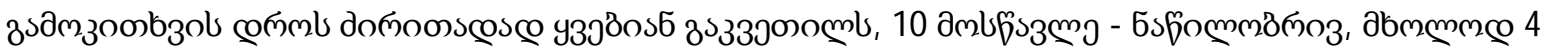

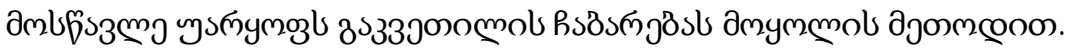

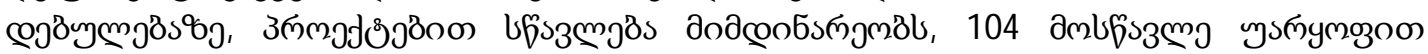

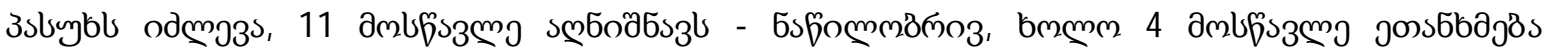

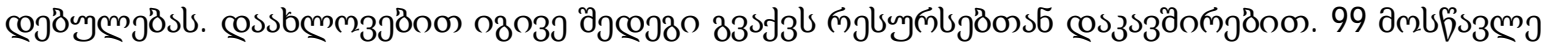

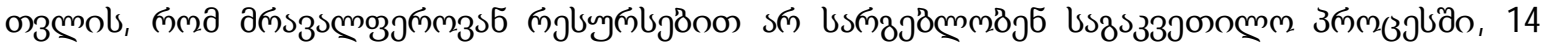

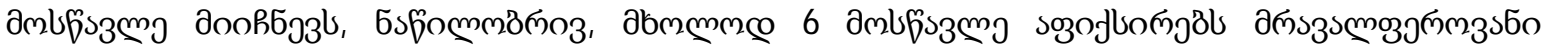

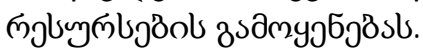

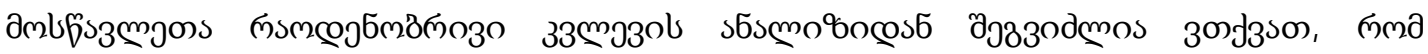

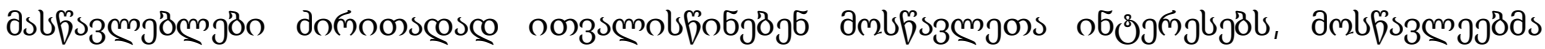

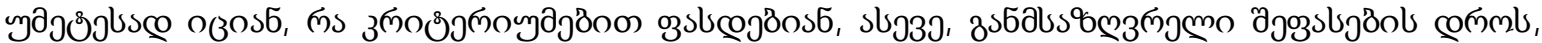

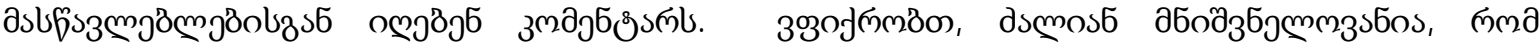

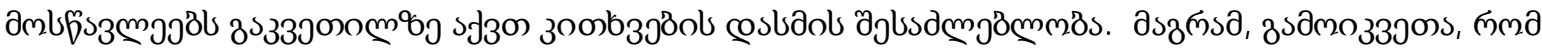

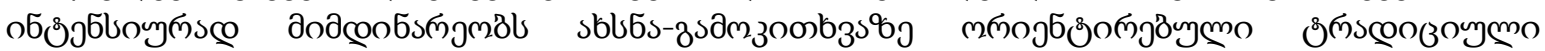

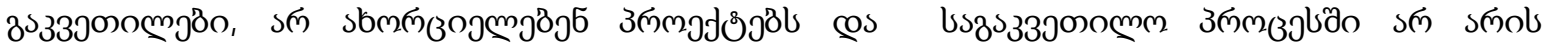

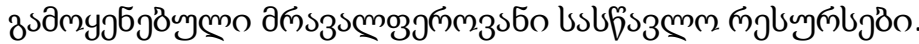

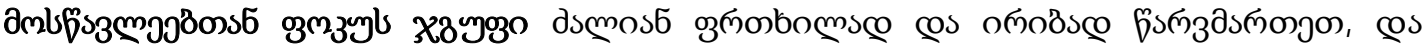

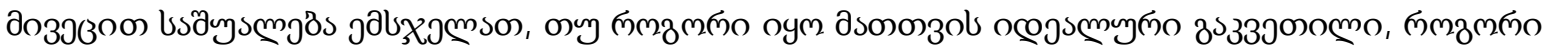

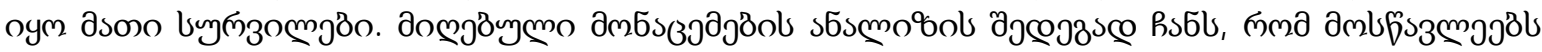

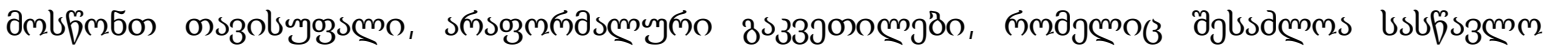

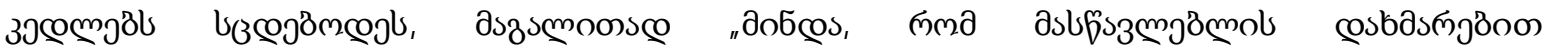

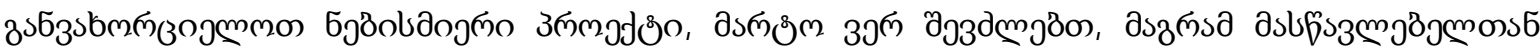

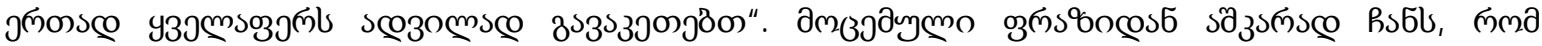

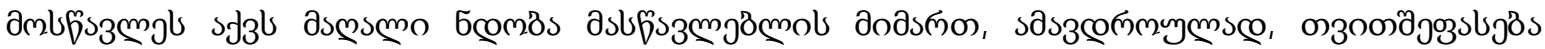

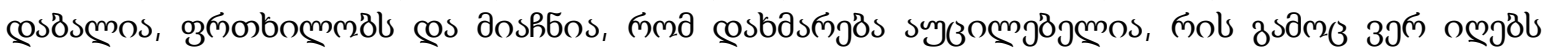

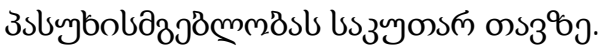

uso6శీj๓

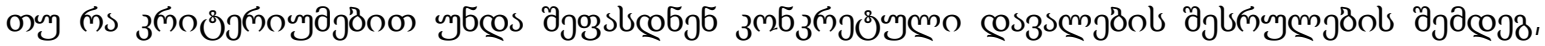

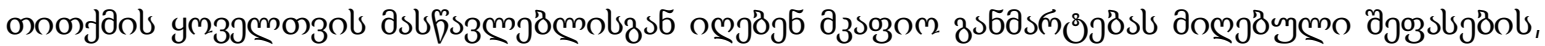

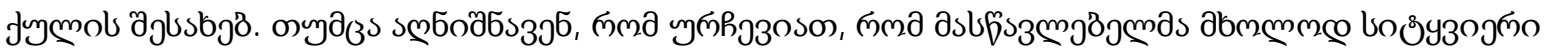

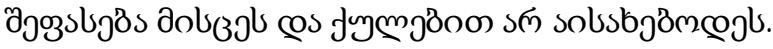

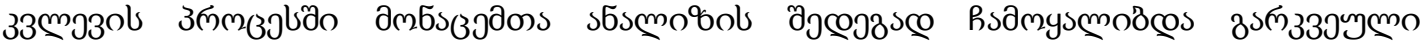

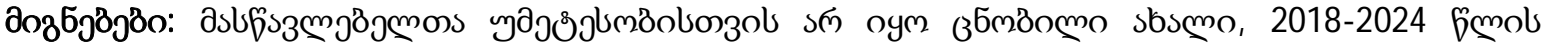

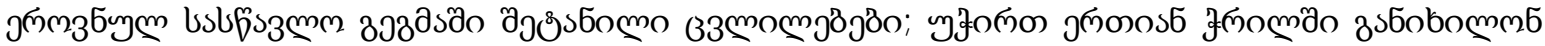

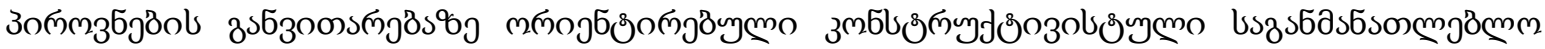

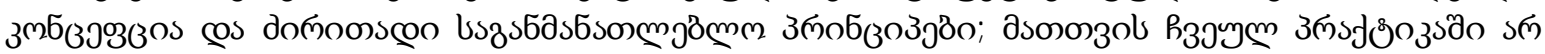

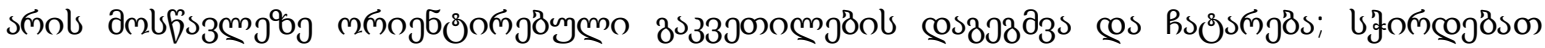

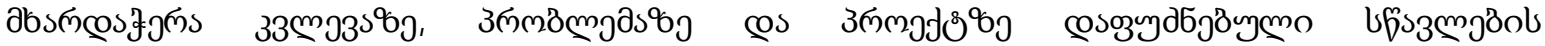

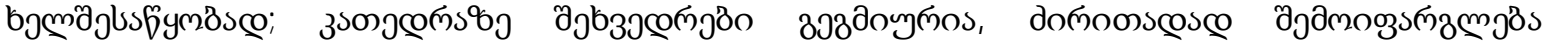

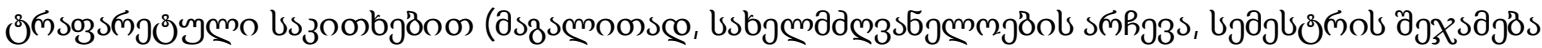

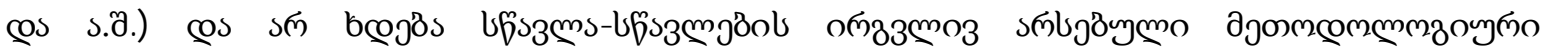

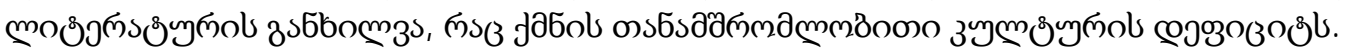

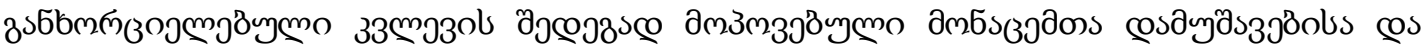

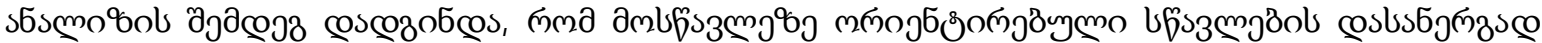

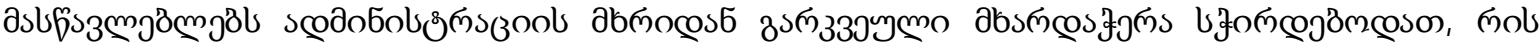

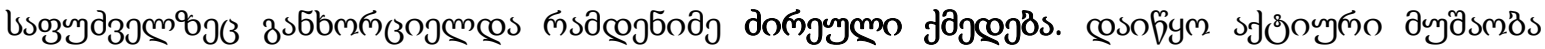

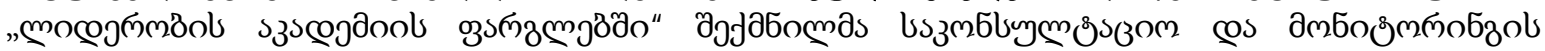

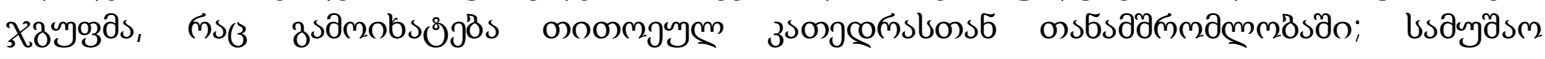




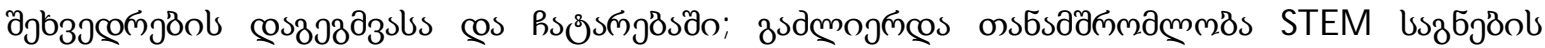

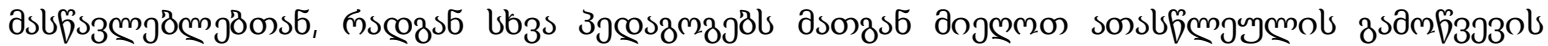

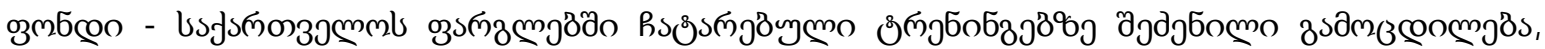

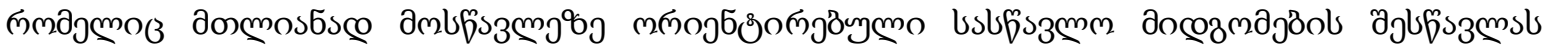

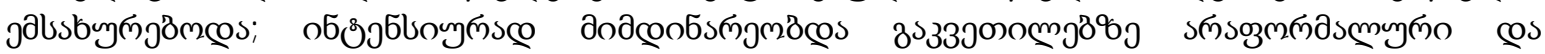

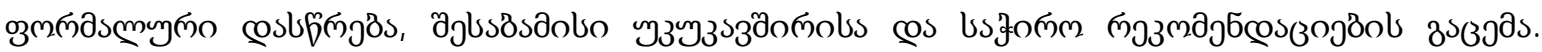

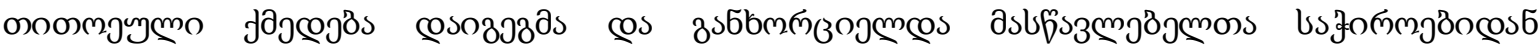

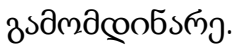

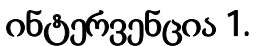

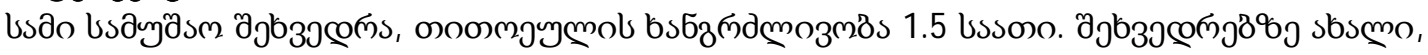

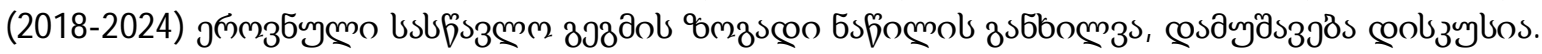

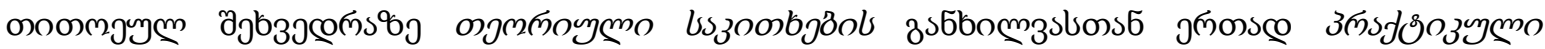
dÿzsm8s cos bo

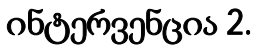

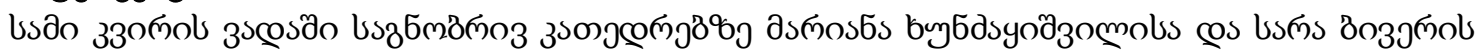

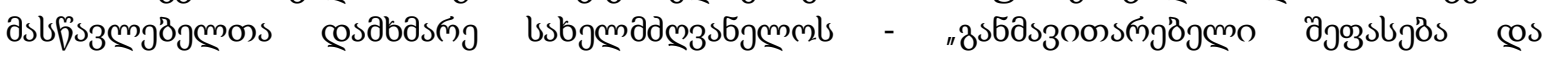

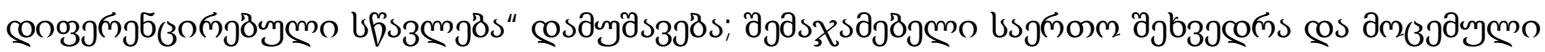
моఠ์

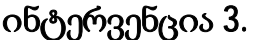

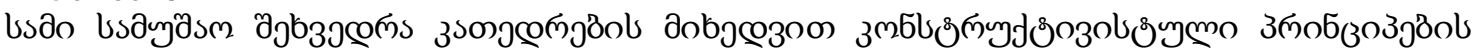

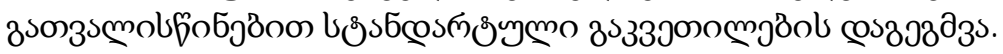

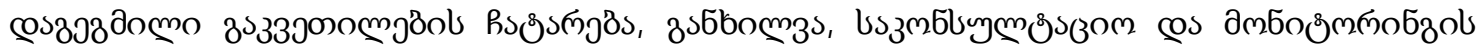

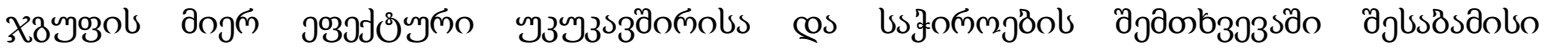

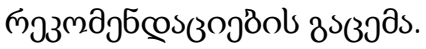

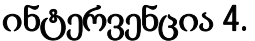

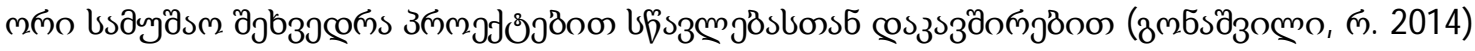

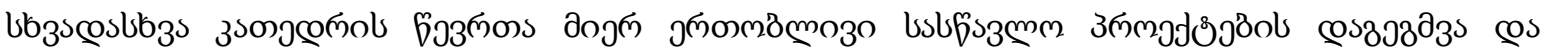

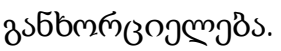

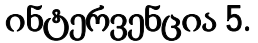

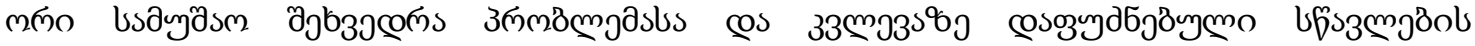

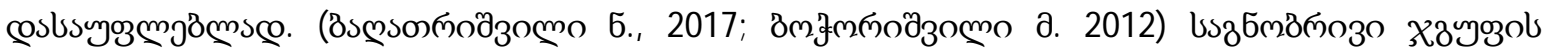

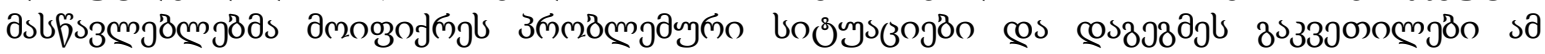

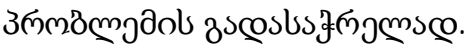

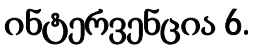

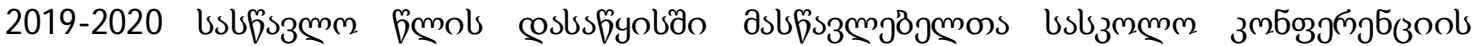

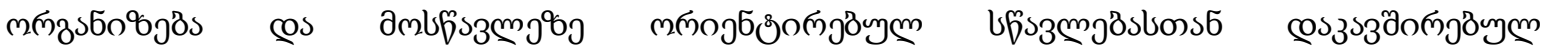

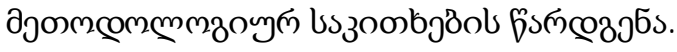

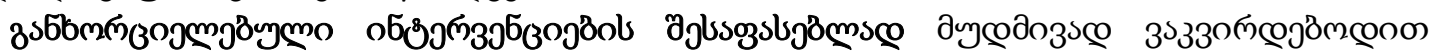

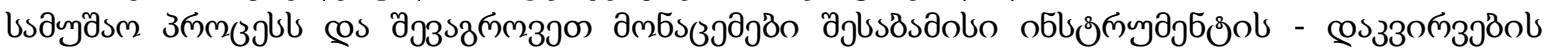

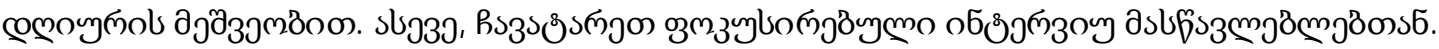

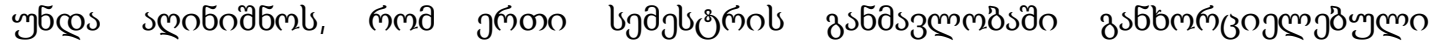

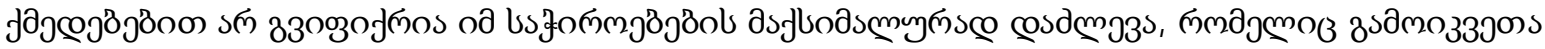

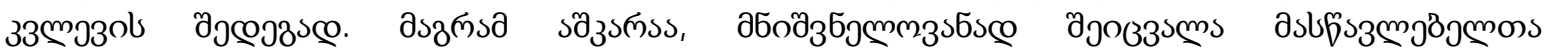

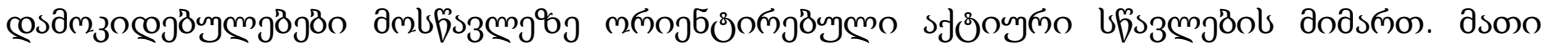

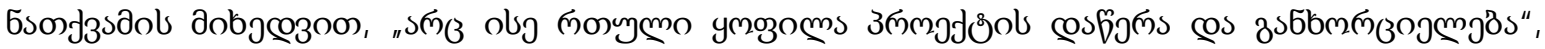

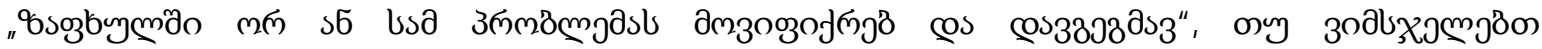

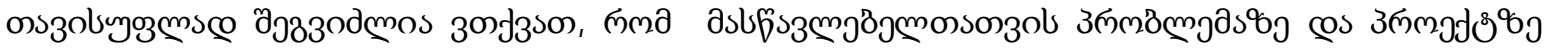

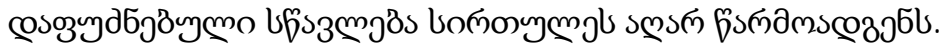

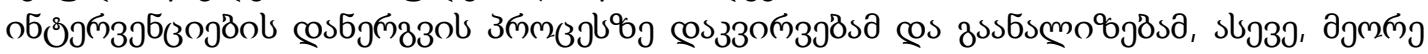

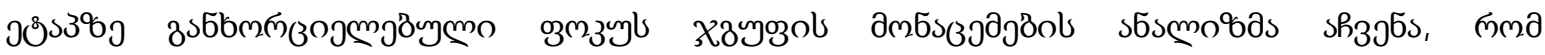




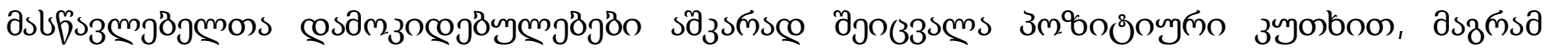

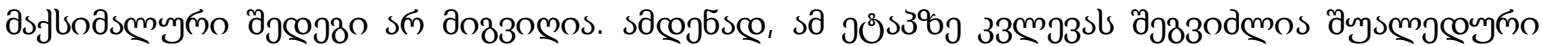

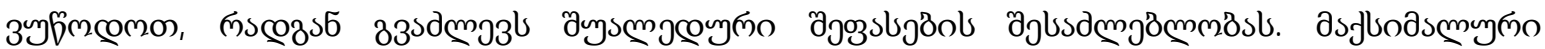

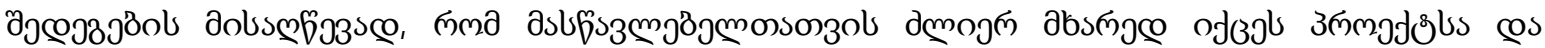

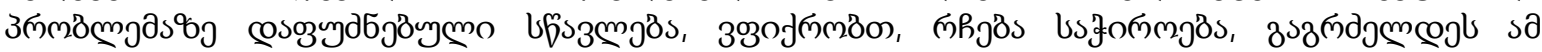

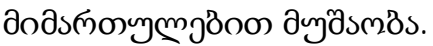

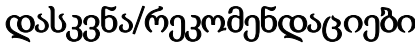

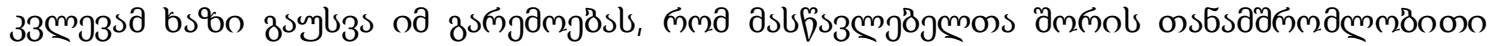

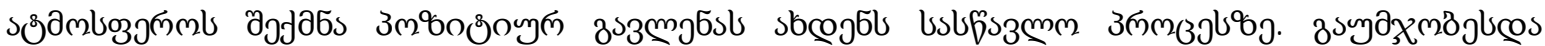

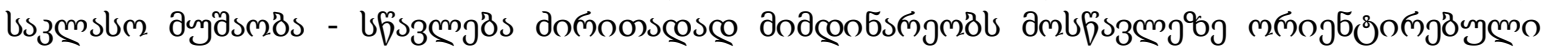

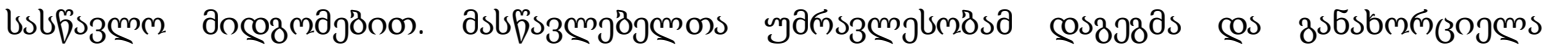

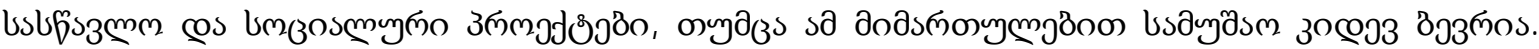

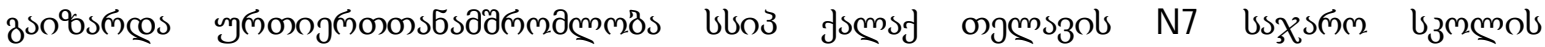

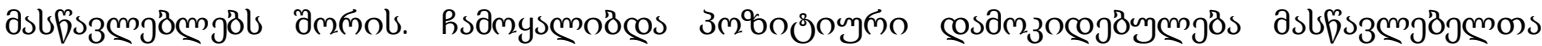

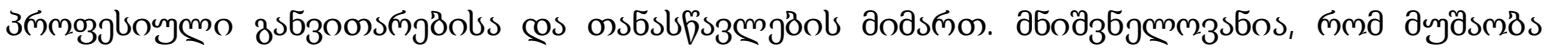

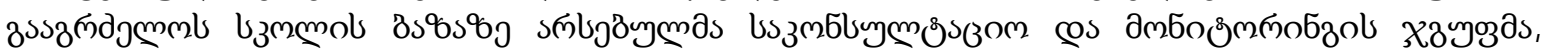

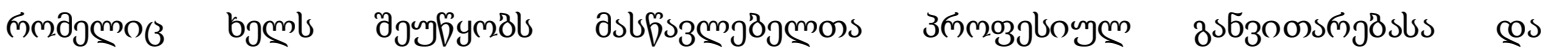

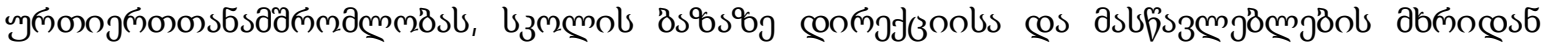

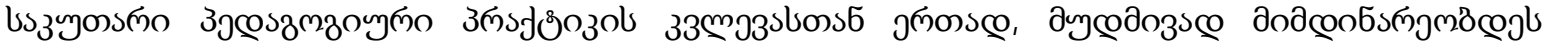
33ल

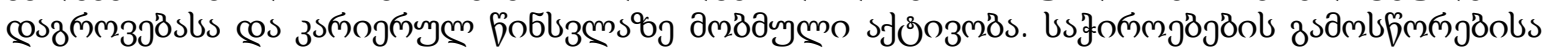

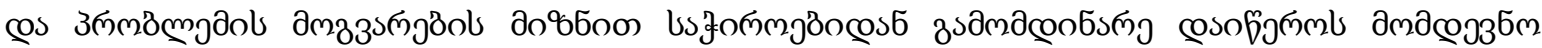

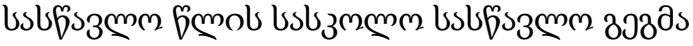

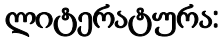

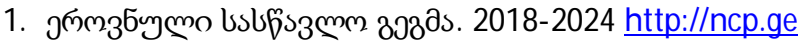

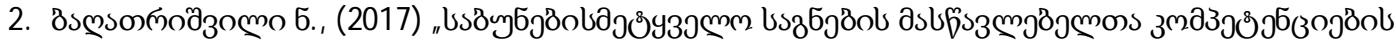

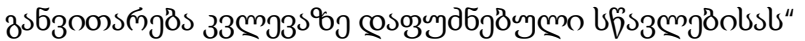
http://tesau.edu.ge/files/uploads/gabatlebis fakulteti/sadisertacio_cnobari/nino/2/_ 18.11.17_last.pdf

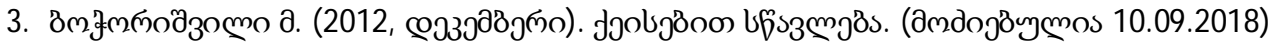
http://mastsavlebeli.ge/?p=2445

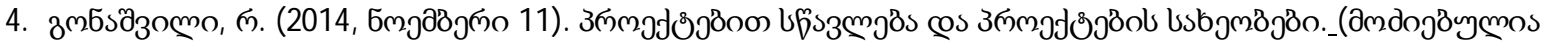
20.10.2018) http://mastsavlebeli.ge/?p=1844

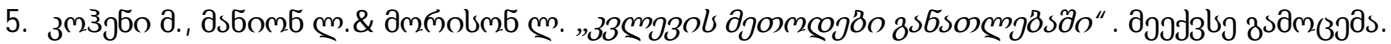

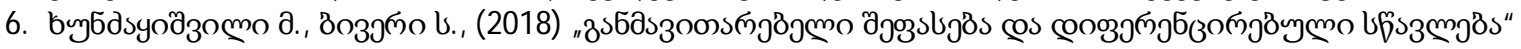
ubo3 dsuf́sз

7. Fuller, F. F. (1969). Concerns of teachers: A developmental conceptualization. A merican educational research journal, 6 (2), 207-226.

8. Newman, I., \& Benz, C. R. (1998). Qualitative-quantitative research methodology: Exploring the interactive continuum. SIU Press. 


\title{
Teacher Attitudes and Collaboration towards the Concept of Student-Centered Lesson
}

Baghatrishvili Natela Iakob Gogebashvili Telavi State University, Telavi

LEPL Telavi Public School №7

Modebadze Nino

lakob Gogebashvili Telavi State University, Telavi

\begin{abstract}
The article is based on a needs assessment carried out at Telavi Public School N7 to understand teachers' attitudes towards student-centered learning strategies. In particular, it examines how intensively and effectively student-centered approaches are integrated into the teaching process and how teachers interact with each other in student-centered learning. The study was carried out in the 2018-2019 academic year, but the inspiration for the study was the Directorate's informal participation in the educational process during the 2017-2018 academic year. A mixed type of study with quantitative and qualitative methods was used to test the hypotheses. To further investigate the problem and identify a common need, teachers from Telavi State School No. 7, as well as elementary and secondary school students, participated in the study. The interventions were carried out after the completion of the first phase of the study. Observing and analyzing teacher activities helped us assess the effectiveness of our problem-solving and needs-based interventions. The study highlights the fact that creating a collaborative atmosphere between teachers has a positive effect on the learning process. The study found the importance of fostering a culture of collaboration among teachers through the use of diverse resources, activities and challenging classroom assignments. Students' views, opinions and feelings about such lessons were also determined. As a result of the analysis, conclusions were drawn that allow recommendations to be made for identifying and solving similar problems and needs.
\end{abstract}

Keywords: Study the School N eeds; Student-Centered Learning 